\title{
Overcoming the Digital Divide in the Post-COVID-19 "Reset": Enhancing Group Virtual Visits with Community Health Workers
}

Megha K Shah $^{1 *}$, MD, MSc; Ashley Christina Gibbs ${ }^{1^{*}}$, MSc; Mohammed K Ali ${ }^{1,2^{*}}$, MD, MSc, MBA; K M Venkat Narayan $^{2 *}, \mathrm{MD}, \mathrm{MSc}, \mathrm{MBA}$; Nadia Islam ${ }^{3 *}, \mathrm{PhD}$

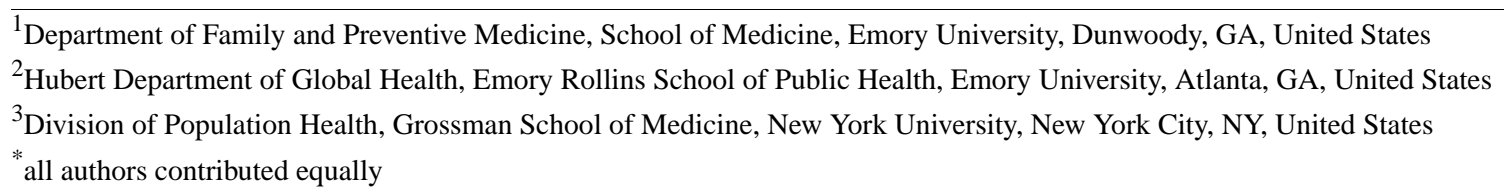

Corresponding Author:

Megha K Shah, MD, MSc

Department of Family and Preventive Medicine

School of Medicine

Emory University

4500 N Shallowford Rd

Dunwoody, GA, 30338

United States

Phone: 14047786944

Fax: 14047786901

Email: mkshah@emory.edu

\begin{abstract}
The COVID-19 pandemic created numerous barriers to the implementation of participant-facing research. For most, the pandemic required rapid transitioning to all virtual platforms. During this pandemic, the most vulnerable populations are at highest risk of falling through the cracks of engagement in clinical care and research. Nonetheless, we argue that we should reframe the discussion to consider how this transition may create opportunities to engage extensively to reach populations. Here, we present our experience in Atlanta (Georgia, United States) in transitioning a group visit model for South Asian immigrants to a virtual platform and the pivotal role community members in the form of community health workers can play in building capacity among participants. We provide details on how this model helped address common barriers to group visit models in clinical practice and how our community health worker team innovatively addressed the digital challenges of working with an elderly population with limited English proficiency.
\end{abstract}

(J Med Internet Res 2021;23(7):e27682) doi: $\underline{10.2196 / 27682}$

\section{KEYWORDS}

community health workers; COVID-19; diabetes mellitus; eHealth; elderly; health equity; telemedicine; virtual; vulnerable populations

\section{Introduction}

The rapid adoption and escalation of telemedicine during the current COVID-19 pandemic has led to concerns about widening gaps in health equity [1]. Among populations with limited digital access or literacy, notable gaps in access to care have been found; for example, less than one-third of Medicare beneficiaries aged over 65 years have reported digital access at home, and those aged over 75 years and with less than high school-level education are less likely to use technology for health care needs $[2,3]$. Potentially vulnerable groups include underserved racial and ethnic groups, older adults, and adults with limited English proficiency (LEP), for whom barriers to care access and health information technology have been well-documented, exacerbated by the pandemic, and are at risk of exacerbation [3-8].

In addition, the pandemic and social distancing guidelines have profoundly limited the ability of vulnerable populations to access reliable health care $[9,10]$. Particularly for chronic disease prevention and management, this can lead to delays in care, which may result in poor health outcomes. Over $40 \%$ of respondents in a recent survey of over 5000 adults in the United States reported delaying or avoiding care owing to concerns 
related to COVID-19, which has been linked to excess deaths reported in 2020, compared to prior years [9]. Older adults, people of color, and low-income individuals-the same populations with the lowest telemedicine access and literacy — have been disproportionately afflicted by COVID-19 and are at the highest risk of cardiometabolic disease [11,12]. The confluence of health risk and the digital divide in these communities creates an environment in which these groups may be most vulnerable to gaps in care and social isolation, which are factors known to exacerbate chronic health conditions.

Despite these challenges, virtual group visits led by community health workers (CHWs) - trained public health professionals with shared lived experience of the communities they serve-may be a pivotal strategy to help address the digital divide in telehealth and foster social connectedness. Social connections can not only influence the risk of chronic illness but also improve chronic disease management [13,14]. Social support is considered a major component of chronic disease self-management [15]. Previous studies suggest that adults with limited social interactions are less likely to engage in health behaviors such as physical activity, smoking cessation, and healthy eating habits [16]. To address this and stimulate socially cohesive and supportive care, group visits have emerged as a type of visit format in which a portion of the visit is a group education class, which can be led by a health coach, nutritionist, or medical assistant, and a portion of time is spent in a brief one-on-one visit with a clinician. Nonetheless, the implementation of group visits has some challenges [17,18]. These challenges include visit-level challenges such as the logistics of clinic workflow and meeting space, patient-level factors such as scheduling or transportation conflicts, and group-leader level challenges such as comfort level in a group role and engaging and retaining participants.

Group visits can be enhanced by meeting patients where they live, work, and worship. CHWs are trained and trusted members of their community, who can serve as a bridge between clinical and community settings. CHWs can work in a variety of capacities to support health education, treatment adherence, health system navigation, and linkage to social services for some of the most vulnerable populations with chronic health conditions [19]. Integrating CHWs into and having them lead group visits may be a particularly effective approach to engaging patients in socially cohesive activities because of CHWs' familiarity with the communities that they work with. Often, they have shared experiences that enhance rapport-building with patients. A systematic review reported that chronic disease management interventions that included $\mathrm{CHW}$ s were associated with increases in tobacco cessation, improved blood pressure control, and low blood sugar levels, with no risk of adverse events [20].

In the current context of the COVID-19 pandemic, virtual group visits may have additional challenges but also expose unanticipated advantages to address the digital divide. Here, we describe our experience transitioning from in-person to a virtual $\mathrm{CHW}$-guided group visit intervention for diabetes and hypertension management among older South Asian adults with LEP.

\section{DREAM Atlanta}

Funded by the National Institutes of Health, the DREAM Atlanta study was designed to test the effectiveness of CHW-delivered in-person health education on diabetes and hypertension, which was tailored for South Asian adults living in Atlanta. Over the course of 6 months, those in the intervention group were intended to receive 5 group education sessions and 2 one-on-one home visits. Initiated in the fall of 2019, the pandemic forced the program's transition to virtual group visits immediately at the start of recruitment. The transition to a virtual program necessitated not only training of CHWs and other study staff in utilizing technology to deliver remote sessions, but also to educate study participants to utilize digital devices and access virtual platforms. Among the 190 adults of South Asian descent enrolled in the program, all reported English as a second language. At baseline, participants were on average, 56 (range $30-80$ ) years old, approximately $40 \%$ of whom were over the age of 60 years; $56 \%$ were female; $44 \%$ were male; and $96 \%$ reported having access to a smartphone or tablet device.

The CHWs worked one-on-one with participants to address barriers to engaging with remote technologies such as creating email accounts, downloading apps on smart devices, and teaching participants how to use features of videoconferencing such as the video and mute features. CHWs utilized several strategies to help participants connect.

\section{Rapid Transition Assessment Methods and Findings}

To gather the perspectives of the study team on the transition to virtual group visits, a 90-minute, tape-recorded video group discussion was conducted with 3 CHWS and the study coordinator. Discussion topics included a discussion of feasibility to conduct virtual recruitment and study sessions, barriers to implementing the study virtually, and specific adaption processes utilized. These data were supplemented with reviews of meeting minutes from weekly team meetings held from March to December 2020. The first and senior authors reviewed common themes emerging from the group discussion and reviews of meeting minutes to determine key facilitators and barriers to the implementation of the remote intervention. All study activities conducted were reviewed by the institutional review board of the New York University School of Medicine, which served as the single institutional review board for this study.

Table 1 lists the digital challenges and solutions fostered by the CHW team. For example, CHWs would start with technologies that participants were familiar with to help them learn to log on to the videoconferencing apps. Most of the DREAM study participants accessed the internet on their smartphones, and similar to studies in South Asia, participants report familiarity with platforms such as Facebook and WhatsApp [21]. Thus, for example, if participants used WhatsApp, the CHW would ask them to join a video call on this platform to help them understand the process of connecting to study-approved remote platforms such as Zoom. This teach back method by the CHWs 
to their participants greatly enhanced their confidence to schedule and lead group virtual visit sessions.

In the 5 months of this transition, we have observed CHWs' unique strengths to help close the digital divide in this highly vulnerable population. While previous studies have demonstrated the effectiveness of mobile technologies for chronic health conditions, including diabetes self-management, few studies have examined or reported on the process of getting participants connected to telehealth platforms [22,23]. However, technical challenges and education of patients about telehealth services are well-documented challenges for health systems' implementation of telehealth services [24]. Similar to our experience, a recent systematic review identified participant training in videoconferencing by an information technology specialist or a group facilitator as a method to overcome participant challenges to connect for psychotherapy interventions [25]. Thus, our findings add to and may have broader implications to address the known challenges of user-related technical difficulties associated with virtual health services.

Table 1. Digital challenges and strategies used by community health workers to enhance attendance in virtual group visits among South Asian adults with limited English proficiency.

\begin{tabular}{|c|c|c|}
\hline Digital challenge & Strategy or modification & Example or representative quote \\
\hline $\begin{array}{l}\text { Community health workers } \\
\text { had limited experience with } \\
\text { videoconferencing software }\end{array}$ & $\begin{array}{l}\text { In-person sessions with the project coordinator } \\
\text { and trial and error with the platform to learn to } \\
\text { use features }\end{array}$ & $\begin{array}{l}\text { - "The project coordinator met with us [the CHWs] in the } \\
\text { office and we created the initial set up and user experience } \\
\text { for zoom." } \\
\text { "There was steady progress with features such as using the } \\
\text { chat box, chatting, and muting participants as the CHWs } \\
\text { became more familiar with interface [sic]." }\end{array}$ \\
\hline
\end{tabular}

Participants did not know how to download apps on their smartphone

- Call the participant or involve a family member and walk them through the steps to download the app

- $\quad$ Provide in-language and empowerment to help participants address frustrations with new technology

Challenges with scanning consent forms or other survey documents

Participants did not have email addresses to receive study documents

- $\quad$ Provide real-time virtual or telephone assistance to troubleshoot issues with documents rather than waiting for weekly meetings or follow-up meetings or calls

- Involve family members who can provide email addresses or support participants

- Choose a communication strategy that the participant might be familiar with, such as a text messaging platform

Participants did not know how to $\log$ in to Zoom

Internet connectivity challenges
- Involve family members in the meetings

- Schedule meetings on the basis of the availability of other family members
- "[We] encourage the participant that a challenge they experience is common (such as problems with the audio), and this encourages the participant to continue to work through the technical situation."
- "At the time that the $\mathrm{CHW} /$ participant needs to send a form, they call the coordinator/CHW to learn the skill. The person receiving the form then sometimes makes quick edits to the form to make it legible or printable."

\section{"It is often easier to send a link through text message or WhatsApp than email. In general, email proficiency of the participants has not change over time. It is not seen as an} easy form of communication in the community."

- $\quad$ "We ask family members when they will be available and try to schedule sessions at those times."
- Be flexible with scheduling and offer assistance at multiple times and days of the week, including weekends and evenings to attend sessions

- Change to audio only or telephone sessions if participants cannot connect
- "Multiple family members may be using the same smartphone for internet; thus, we offer our sessions on the weekend and evenings and often have to reschedule to make sure participants can attend [sic]."
Moreover, they have addressed several known challenges of group visits, which are both participant- and visit-related. Firstly, the barrier of adequate transportation, particularly acute in large, diffuse urban areas including Atlanta—which has limited public transportation options - can prevent participants from attending group visits. Previous studies on barriers to participation in group medical visits include the lack of transportation or scheduling conflicts [26,27]; nonetheless, by offering this virtual option, participants report that this has facilitated their ability to engage in the intervention. One female CHW commented, "For our participants, Zoom is better, because they don't need to get ready or drive anywhere. We are able to spend more time with them."
Logistical issues of meeting spaces and workflow can lead to inefficiency and be time-intensive for group visit implementation in clinical practice $[27,28]$. The transition to virtual visits has provided flexibility to the team for scheduling and location, which has likely enhanced participation and engagement and improved the efficiency of the visits. The CHWs report having more flexibility to conduct multiple sessions, if needed, to facilitate participation, as these logistical obstacles are easier to overcome in virtual sessions.

Lastly, all participants share a common background and health conditions. Shared personal health characteristics can greatly enhance participation and patient activation, leading to improved benefits and health outcomes from group visits [26,28]. While 
still in progress, the retention rate is $>90 \%$ toward the fifth month of this 6-month program. At the height of the pandemic, at a time when older adults of underserved racial and ethnic communities with LEP were at the greatest risk of social isolation, the virtual group visits have provided much welcomed social interaction for these at-risk individuals. One female CHW commented, "They [participants] are bored at home; now they are eagerly awaiting our sessions!"

While this pandemic has certainly strained most aspects of well-being for a majority of individuals, there are opportunities to shape our "new normal." Namely, for communities of color, older adults, and those with LEP, where the risk of the digital divide and social isolation may widen, investing in resources, including CHW-led group virtual visits, may help address gaps in care. The group visit model offers the opportunity to enhance social interaction and patient activation, and preliminary results from our study indicate that the virtual group visit is feasible and acceptable for older adults with LEP. Further, we believe that the involvement of CHWs is critical to this process, to help bridge the digital void that is at risk of widening further during this ongoing pandemic and to enhance the digital literacy of our most vulnerable populations. Beyond the current pandemic, we believe that this model is feasible and can continue to reach our most vulnerable populations in the future.

\section{Acknowledgments}

We would like to acknowledge the dedicated work of our CHWs, Sakila Nasrin, Zohra Amin, and Nazneen Akter, who have committed themselves to the success of our study in spite of the challenges faced during the COVID-19 pandemic. We would also like to acknowledge our DREAM partners in New York City for their mentorship and guidance. This study was supported by National Institute on Minority Healthy and Health Disparities (K23 MD015088-01 and 3U54MD000538-17S1). MKA and KMV received support from P30DK111024 awarded by the Georgia Center for Diabetes Translation Research, funded by the National Institute of Diabetes and Digestive and Kidney Diseases. The funders did not play a role in the design, collection, analysis, or drafting of the manuscript. NI is partially supported by the National Institutes of Health, National Institute of Diabetes and Digestive and Kidney Diseases (grants R01DK110048-01A1, R18DK110740, and P30 DK111022R01DK11048), National Heart, Lung, and Blood Institute (grant 1UG3HL151310), and National Center for Advancing Translational Science (grant UL1TR001445); and by the Centers for Disease Control and Prevention (grant U48DP001904).

\section{Conflicts of Interest}

None declared.

\section{References}

1. Nouri S, Khoong EC, Lyles CR, Karliner L. Addressing Equity in Telemedicine for Chronic Disease Management During the Covid-19 Pandemic. NEJM Catalyst 2020;1(3) [FREE Full text] [doi: 10.1056/cat.20.0131]

2. Roberts ET, Mehrotra A. Assessment of Disparities in Digital Access Among Medicare Beneficiaries and Implications for Telemedicine. JAMA Intern Med 2020 Oct 01;180(10):1386-1389. [doi: 10.1001/jamainternmed.2020.2666] [Medline: 32744601]

3. Gordon NP, Hornbrook MC. Differences in Access to and Preferences for Using Patient Portals and Other eHealth Technologies Based on Race, Ethnicity, and Age: A Database and Survey Study of Seniors in a Large Health Plan. J Med Internet Res 2016 Mar 04;18(3):e50 [FREE Full text] [doi: 10.2196/jmir.5105] [Medline: 26944212]

4. Din HN, McDaniels-Davidson C, Nodora J, Madanat H. Profiles of a Health Information-Seeking Population and the Current Digital Divide: Cross-Sectional Analysis of the 2015-2016 California Health Interview Survey. J Med Internet Res 2019 May 14;21(5):e11931 [FREE Full text] [doi: 10.2196/11931] [Medline: 31094350]

5. Chunara R, Zhao Y, Chen J, Lawrence K, Testa P, Nov O, et al. Telemedicine and healthcare disparities: a cohort study in a large healthcare system in New York City during COVID-19. J Am Med Inform Assoc 2021 Jan 15;28(1):33-41 [FREE Full text] [doi: 10.1093/jamia/ocaa217] [Medline: 32866264]

6. Yoon H, Jang Y, Vaughan PW, Garcia M. Older Adults' Internet Use for Health Information: Digital Divide by Race/Ethnicity and Socioeconomic Status. J Appl Gerontol 2020 Jan;39(1):105-110. [doi: 10.1177/0733464818770772] [Medline: 29661052]

7. Nguyen A, Mosadeghi S, Almario CV. Persistent digital divide in access to and use of the Internet as a resource for health information: Results from a California population-based study. Int J Med Inform 2017 Jul;103:49-54. [doi:

10.1016/j.ijmedinf.2017.04.008] [Medline: 28551001]

8. Casillas A, Moreno G, Grotts J, Tseng C, Morales LS. A Digital Language Divide? The Relationship between Internet Medication Refills and Medication Adherence among Limited English Proficient (LEP) Patients. J Racial Ethn Health Disparities 2018 Dec;5(6):1373-1380 [FREE Full text] [doi: 10.1007/s40615-018-0487-9] [Medline: 29600351]

9. Czeisler MÉ, Marynak K, Clarke KE, Salah Z, Shakya I, Thierry JM, et al. Delay or Avoidance of Medical Care Because of COVID-19-Related Concerns - United States, June 2020. MMWR Morb Mortal Wkly Rep 2020 Sep 11;69(36):1250-1257 [FREE Full text] [doi: 10.15585/mmwr.mm6936a4] [Medline: 32915166]

10. Pollack HA, Kelly C. COVID-19 And Health Disparities: Insights From Key Informant Interviews. Health Affairs Blog. 2020 Oct 27. URL: https://www.healthaffairs.org/do/10.1377/hblog20201023.55778/full/ [accessed 2020-12-15] 
11. Clark A, Jit M, Warren-Gash C, Guthrie B, Wang HHX, Mercer SW, Centre for the Mathematical Modelling of Infectious Diseases COVID-19 working group. Global, regional, and national estimates of the population at increased risk of severe COVID-19 due to underlying health conditions in 2020: a modelling study. Lancet Glob Health 2020 Aug;8(8):e1003-e1017 [FREE Full text] [doi: 10.1016/S2214-109X(20)30264-3] [Medline: 32553130]

12. CDC COVID-19 Response Team. Preliminary Estimates of the Prevalence of Selected Underlying Health Conditions Among Patients with Coronavirus Disease 2019 - United States, February 12-March 28, 2020. MMWR Morb Mortal Wkly Rep 2020 Apr 03;69(13):382-386 [FREE Full text] [doi: 10.15585/mmwr.mm6913e2] [Medline: 32240123]

13. Christakis NA, Fowler JH. The spread of obesity in a large social network over 32 years. N Engl J Med 2007 Jul 26;357(4):370-379. [doi: 10.1056/NEJMsa066082] [Medline: 17652652]

14. Cunningham SA, Adams SR, Schmittdiel JA, Ali MK. Incidence of diabetes after a partner's diagnosis. Prev Med 2017 Dec;105:52-57 [FREE Full text] [doi: 10.1016/j.ypmed.2017.08.020] [Medline: 28823754]

15. Strom JL, Egede LE. The impact of social support on outcomes in adult patients with type 2 diabetes: a systematic review. Curr Diab Rep 2012 Dec;12(6):769-781 [FREE Full text] [doi: 10.1007/s11892-012-0317-0] [Medline: 22949135]

16. Kobayashi LC, Steptoe A. Social Isolation, Loneliness, and Health Behaviors at Older Ages: Longitudinal Cohort Study. Ann Behav Med 2018 May 31;52(7):582-593 [FREE Full text] [doi: 10.1093/abm/kax033] [Medline: 29860361]

17. Careyva BA, Johnson MB, Goodrich SA, Shaak K, Stello B. Clinician-Reported Barriers to Group Visit Implementation. J Prim Care Community Health 2016 Jul;7(3):188-193 [FREE Full text] [doi: 10.1177/2150131916631924] [Medline: 26883437]

18. Thompson C, Meeuwisse I, Dahlke R, Drummond N. Group medical visits in primary care for patients with diabetes and low socioeconomic status: users' perspectives and lessons for practitioners. Can J Diabetes 2014 Jun;38(3):198-204. [doi: 10.1016/j.jcjd.2014.03.012] [Medline: 24909090]

19. Peretz PJ, Islam N, Matiz LA. Community Health Workers and Covid-19 - Addressing Social Determinants of Health in Times of Crisis and Beyond. N Engl J Med 2020 Nov 05;383(19):e108. [doi: 10.1056/NEJMp2022641] [Medline: 32966715]

20. Jeet G, Thakur JS, Prinja S, Singh M. Community health workers for non-communicable diseases prevention and control in developing countries: Evidence and implications. PLoS One 2017;12(7):e0180640 [FREE Full text] [doi: 10.1371/journal.pone.0180640] [Medline: 28704405]

21. Prinjha S, Ricci-Cabello I, Newhouse N, Farmer A. British South Asian Patients' Perspectives on the Relevance and Acceptability of Mobile Health Text Messaging to Support Medication Adherence for Type 2 Diabetes: Qualitative Study. JMIR Mhealth Uhealth 2020 Apr 20;8(4):e15789 [FREE Full text] [doi: 10.2196/15789] [Medline: $\underline{32310150]}$

22. Lee J, Choi M, Lee SA, Jiang N. Effective behavioral intervention strategies using mobile health applications for chronic disease management: a systematic review. BMC Med Inform Decis Mak 2018 Feb 20;18(1):12 [FREE Full text] [doi: 10.1186/s12911-018-0591-0] [Medline: 29458358]

23. Narasimha S, Madathil KC, Agnisarman S, Rogers H, Welch B, Ashok A, et al. Designing Telemedicine Systems for Geriatric Patients: A Review of the Usability Studies. Telemed J E Health 2017 Jun;23(6):459-472. [doi:

10.1089/tmj.2016.0178] [Medline: 27875667]

24. Ellimoottil C, An L, Moyer M, Sossong S, Hollander JE. Challenges And Opportunities Faced By Large Health Systems Implementing Telehealth. Health Aff (Millwood) 2018 Dec;37(12):1955-1959. [doi: 10.1377/hlthaff.2018.05099] [Medline: 30633667]

25. Banbury A, Nancarrow S, Dart J, Gray L, Parkinson L. Telehealth Interventions Delivering Home-based Support Group Videoconferencing: Systematic Review. J Med Internet Res 2018 Feb 02;20(2):e25 [FREE Full text] [doi: 10.2196/jmir.8090] [Medline: 29396387]

26. Wadsworth KH, Archibald TG, Payne AE, Cleary AK, Haney BL, Hoverman AS. Shared medical appointments and patient-centered experience: a mixed-methods systematic review. BMC Fam Pract 2019 Jul 08;20(1):97 [FREE Full text] [doi: 10.1186/s12875-019-0972-1] [Medline: 31286876]

27. Jaber R, Braksmajer A, Trilling JS. Group visits: a qualitative review of current research. J Am Board Fam Med 2006;19(3):276-290 [FREE Full text] [doi: 10.3122/jabfm.19.3.276] [Medline: 16672681]

28. Edelman D, Gierisch JM, McDuffie JR, Oddone E, Williams JW. Shared medical appointments for patients with diabetes mellitus: a systematic review. J Gen Intern Med 2015 Jan;30(1):99-106 [FREE Full text] [doi: 10.1007/s11606-014-2978-7] [Medline: 25107290]
Abbreviations
CHW: community health worker
LEP: limited English proficiency 
Edited by $R$ Kukafka; submitted 02.02.21; peer-reviewed by K Baucom, D Petsani; comments to author 26.03.21; revised version received 12.04.21; accepted 14.06.21; published 08.07.21

Please cite as:

Shah MK, Gibbs AC, Ali MK, Narayan KMV, Islam N

Overcoming the Digital Divide in the Post-COVID-19 "Reset": Enhancing Group Virtual Visits with Community Health Workers

$J$ Med Internet Res 2021;23(7):e27682

URL: https://www.jmir.org/2021/7/e27682

doi: $10.2196 / 27682$

PMID: $\underline{34152995}$

CMegha K Shah, Ashley Christina Gibbs, Mohammed K Ali, K M Venkat Narayan, Nadia Islam. Originally published in the Journal of Medical Internet Research (https://www.jmir.org), 08.07.2021. This is an open-access article distributed under the terms of the Creative Commons Attribution License (https://creativecommons.org/licenses/by/4.0/), which permits unrestricted use, distribution, and reproduction in any medium, provided the original work, first published in the Journal of Medical Internet Research, is properly cited. The complete bibliographic information, a link to the original publication on https://www.jmir.org/, as well as this copyright and license information must be included. 